\title{
Three-Year Follow-Up Study in Patients with Guillain-Barré Syndrome
}

\author{
Vesna Martic, Ivo Bozovic, Ivana Berisavac, Ivana Basta, Stojan Peric, \\ Milica Babic, Sonja Lukic Rajic, Bogdan Bjelica, Olivera Stojiljkovic Tamas, \\ Aleksandar Stojanov, Marija Grunauer, Mina Cobeljic, Nenad Komatina, \\ Vanja Djuric, Milutin Petrovic, Balsa Vujovic, Aleksandra Dominovic Kovacevic, \\ Gordana Djordjevic, Dejana Jovanovic, Zorica Stevic
}

\begin{abstract}
Background: A majority of patients with Guillain-Barré syndrome (GBS) have tendency of a good recovery. Our aim was to evaluate the outcome of the disease 1 and 3 years after GBS symptom onset. Methods: During 2014, GBS was diagnosed in 82 patients in seven tertiary healthcare centers. Neurological follow-up was conducted in 57 (70\%) patients after 1 year, and in 54 (66\%) after 3 years. Functional disability was estimated according to the GBS disability scale (GDS), with a score of 0-3 indicating mild disability and a score of 4-6 indicating severe disability during acute phase, whereas a score $>1$ indicated poor recovery on follow-ups. Visual analog scale was used to assess sensory symptoms and musculoskelatal pain, and Krupp's Fatigue Severity Scale was used to asses fatigue. Results: Poor functional outcome was found in 39\% of GBS patients at year 1 and $30 \%$ at year 3. Paresthesias/dysesthesias were detected in $60 \%$ of patients after 1 year and $43 \%$ after 3 years. Musculoskeletal pain was present in $40 \%$ of patients at year 1 and $33 \%$ at year 3 . Significant fatigue after 1 year was found in $21 \%$ of subjects and after 3 years in $7 \%$. Parameters associated with poor functional outcome after 1 year were age $>55$ years $(p=0.05)$, severe disability at admission $(p<0.05)$, and on discharge $(p<0.01)$. Poor functional outcome after 3 years was associated with male gender $(p<0.05)$ and severe disability on discharge $(p=0.06)$. Conclusion: One and even three years after GBS onset, a substantial number of patients had neurological sequelae, including functional disability, sensory symptoms, pain, and fatigue.
\end{abstract}

RÉSUMÉ: Étude de suivi d'une durée de trois ans chez des patients atteints du syndrome de Guillain-Barré. Contexte: La majorité des patients atteints du syndrome de Guillain-Barré (SGB) ont tendance à jouir d'une bonne récupération. Le but de notre étude a donc été d'évaluer l'évolution de cette maladie un an et trois ans après l'apparition de ses premiers symptômes. Méthodes: En 2014, le SGB a été diagnostiqué chez 82 patients ayant fréquenté sept centres de soins de santé de troisième ligne. Un suivi neurologique a été mené au bout d'un an auprès de 57 patients (70\%); et, au bout de trois ans, auprès de 54 d'entre eux (66\%). Leur incapacité fonctionnelle a été évaluée en fonction de l'échelle d'incapacité du SGB. Rappelons qu'un score entre 0 et 3 indique une incapacité légère; qu'un score entre 4 et 6 , une incapacité sévère durant la phase aiguë du syndrome; et finalement qu'un score $>1$ indique une récupération difficile au moment des suivis. L'échelle visuelle analogue (EVA) a aussi été utilisée pour évaluer leurs symptômes sensoriels et leurs douleurs musculo-squelettiques. Enfin, l'échelle de gravité de la fatigue de Krupp a été utilisée pour évaluer leur degré de fatigue. Résultats: La première année, on a observé une piètre amélioration des capacités fonctionnelles chez 39\% des patients atteints du SGB; pour la troisième année, cette proportion était de 30\%. Au bout d'un an, on a aussi détecté la présence de paresthésie/dysesthésie chez $60 \%$ des patients; pour la troisième année, cette proportion était de $43 \%$. Des douleurs musculo-squelettiques ont été rapportées chez $40 \%$ des patients après un an; deux ans plus tard, ce pourcentage chutait à 33\%. Enfin, un état de fatigue important a été noté chez $21 \%$ des patients au bout d'un an; ce pourcentage n'était plus que de $7 \%$ au bout de trois ans. Les paramètres associés à une piètre amélioration des capacités fonctionnelles au bout d'un an étaient l'âge ( $>55$ ans; $\mathrm{p}=0,05)$ ainsi qu'une incapacité sévère au moment de leur admission $(\mathrm{p}<0,05)$ et de leur congé $(\mathrm{p}<0,01)$. Au bout de trois ans, une piètre amélioration des capacités fonctionnelles était associée au sexe masculin $(\mathrm{p}<0,05)$ et à une incapacité sévère au moment d'obtenir un congé $(\mathrm{p}=0,06)$. Conclusions: Un an et trois ans après l'apparition des premiers symptômes du SGB, un nombre important de patients donnaient à voir des séquelles neurologiques, ce qui incluait une forme ou une autre d'incapacité fonctionnelle, des symptômes sensoriels, des douleurs et un état de fatigue.

Keywords: Guillain-Barré syndrome, Prospective study, Functional disability, Pain, Fatigue doi:10.1017/cjn.2018.12

Can J Neurol Sci. 2018;45: 269-274

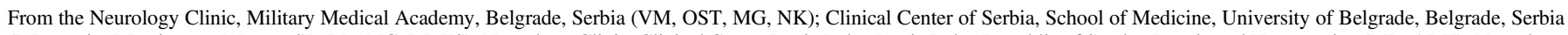

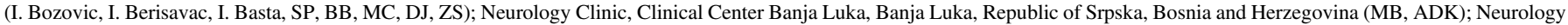

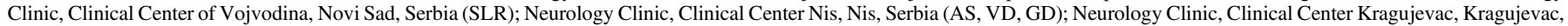
Serbia (MP); Neurology Clinic, Clinical Center of Montenegro, Podgorica, Montenegro (BV).

Received July 5, 2017. Final Revisions Submitted December 18, 2017. Date of AcCeptance January 1, 2018.

Correspondence to: Stojan Peric, Neurology Clinic, Clinical Center of Serbia 6, Dr Subotica Street, 11000 Belgrade, Serbia. Email: stojanperic@ gmail.com
} 


\section{INTRODUCTION}

Guillain-Barré syndrome (GBS) is an autoimmune disease of the peripheral nerves and their roots, which manifests as an acute muscle weakness that usually progresses within 4 weeks. ${ }^{1-3}$ Common features of this disease are monophasic course and diverse clinical outcome.

Guillain-Barré syndrome is a rapidly progressive disorder that commonly causes significant functional disability in the acute phase. Literature data, including the study conducted in our population of patients, point to the fact that more than one-third of GBS patients at nadir, as well as a quarter of patients on discharge, are chair-bound or confined to bed. ${ }^{4}$ Although GBS has a favorable outcome in the majority of patients, a certain number of them could still meet poor outcome with a considerable long-term functional disability that could negatively affect their quality of life..$^{5-7}$

The aim of this prospective study was to estimate the clinical outcome in GBS patients after 1 and 3 years from the acute episode of illness.

\section{MethodS}

The study included GBS patients who were hospitalized in seven tertiary healthcare centers in Serbia, Republic of Srpska (Bosnia and Herzegovina), and Montenegro during 2014. The diagnosis of GBS was made according to the Brighton diagnostic criteria. $^{8}$ Complete neurological evaluation was conducted exactly 1 year ( \pm 7 days) after the onset of GBS. Second retest was done in September 2017-that is, 33-44 months from acute GBS episode (median 37 months, 3 years). This study was approved by the Ethical Board of the Neurology Clinic, Clinical Center of Serbia, and all patients signed informed consent.

Precise diagnosis of GBS and of common subtypes (acute inflammatory demyelinating polyneuropathy, acute motor axonal neuropathy, acute motor and sensory axonal neuropathy, and Miller-Fisher syndrome) was made through clinical and electrophysiological assessment. ${ }^{8-10}$ Preceding events were considered important if they occurred 3-42 days before GBS onset. ${ }^{8}$ Level of functional disability was established according to the GBS disability scale (GDS): 0, absence of symptoms; 1, patients with mild symptoms, who can run; 2, patients who can walk independently at least $5 \mathrm{~m}$, but cannot run; 3 , patients who can walk for $5 \mathrm{~m}$ or more only with assistance; 4 , wheelchair-bound or confined to bed; 5, requirement for assisted ventilation; and 6, lethal outcome. ${ }^{11}$ Functional disability assessment was carried out on admission, at nadir, and on discharge from the medical records, whereas assessment 1 and 3 years after acute GBS episode was carried out by local neurologists who are co-authors of the paper. Mild disability at admission, on nadir, and on discharge was considered if GDS was 0-3, and severe if it was 4-5. Poor functional outcome after 1 or 3 years was defined if GDS score was $>1$, whereas a score of 0-1 was considered as a favorable outcome.

One and three years after the onset of symptoms of GBS, patients were evaluated for subjective sensory deficits (paresthesia and dysesthesia), musculoskeletal pain, and fatigue. Fatigue severity was evaluated according to the Krupp's Fatigue Severity Scale (FSS). It is a nine-item questionnaire that enables patients to assess their current condition using scores on a seven-point scale, with a score above 36 meaning significant fatigue. ${ }^{12}$ Symptom intensity of sensory deficit and musculoskeletal pain was assessed by self-assessment visual analog scale (0-10 points). Scale values
1-3 accounted for the presence of mild disturbances, 4-6 indicated moderate disturbances, and 7-10 indicated severe disturbances. ${ }^{13}$

Normality of data was tested by the Kolmogorov-Smirnov test. Mean, standard deviation, and proportion were used as methods of descriptive statistics. $\chi^{2}$ test was used to analyze the association of sociodemographic (gender, and age above or below 55) and clinical parameters (mild/severe disability at admission, nadir, and on discharge) with the disease outcome at year 1 and year 3 (including good and poor recovery estimated by GDS score, presence of sensory disturbances, musculoskeletal pain, or fatigue). We also analyzed influence of investigated parameters at year 1 on outcome at year 3 using the $\chi^{2}$ test. Multivariant analysis was not performed owing to the small number of cases. Association between disability measured by GDS score, presence of sensory disturbances, musculoskeletal pain, and fatigue at year 1 and year 3 was analyzed using two hierarchical cluster analyses. In this way, we avoided multiple comparisons in a not-so-large cohort. For all statistical tests, significant testing was two-sided, with $\alpha$ set at 0.05 for statistical significance and 0.01 for high statistical significance.

\section{Results}

During 2014, the diagnosis of GBS was confirmed in 82 patients (Figure 1). Three patients died immediately during the hospital stay owing to sudden cardiac death, sepsis, and pulmonary embolism, and other four patients died within the next 12 months

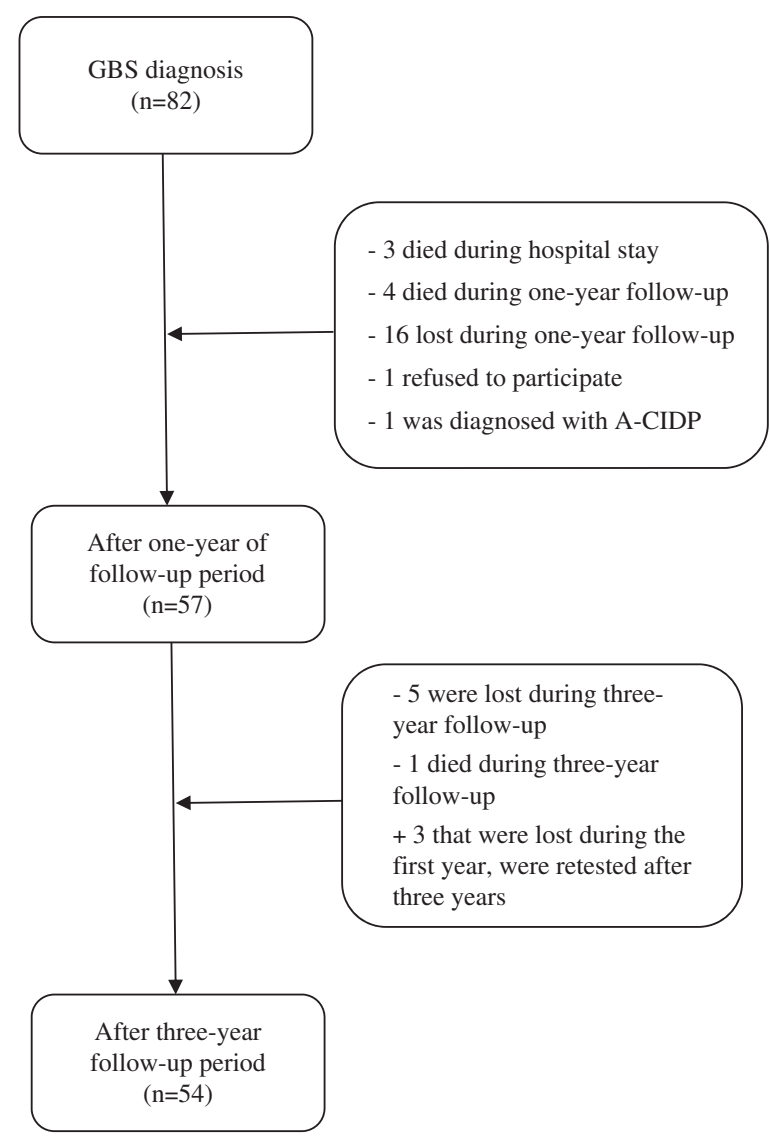

Figure 1: Flowchart representing included and excluded patients. $A-C I D P=$ acute-onset chronic inflammatory polyneuropathy; $G B S=$ Guillain-Barré syndrome 
Table 1: Sociodemographic and clinical features of GuillainBarré syndrome (GBS) patients at time of hospitalization

\begin{tabular}{l|c}
\hline Feature & Group tested after 1 year \\
\hline$n$ & 57 \\
\hline Gender (\% of men) & 62 \\
\hline Age (mean \pm SD, years) & $56 \pm 16$ \\
\hline Number of days to nadir (mean \pm SD) & $10 \pm 7$ \\
\hline Precipitating factor (\%) & 29 \\
\hline Respiratory infection & 13 \\
\hline Gastrointestinal infection & 16 \\
\hline Other & 42 \\
\hline Unknown & 58 \\
\hline GBS subtype (\%) & 7 \\
\hline AIDP & 7 \\
\hline AMSAN & 5 \\
\hline AMAN & 23 \\
\hline MFS & $26 \pm 27$ \\
\hline Equivocal & \\
\hline Hospital stay duration (mean \pm SD, days) & 60 \\
\hline Therapeutic option (\%) & 29 \\
\hline Intravenous immunoglobulin & 11 \\
\hline PE & 93 \\
\hline Supportive treatment only & \\
\hline Rehabilitation & \\
\hline AIDP & \\
\hline & \\
\hline & \\
\hline & \\
\hline & \\
\hline & \\
\hline
\end{tabular}

AIDP $=$ acute inflammatory demyelinating polyradiculoneuropathy; AMAN $=$ acute motor axonal neuropathy; AMSAN = acute motor and sensory axonal neuropathy; GDS = GBS disability scale; MFS $=$ MillerFisher syndrome; $\mathrm{PE}=$ plasma exchange.

owing to sudden cardiac death (two), pulmonary embolism, and car accident. During a 1-year period, 16 patients were lost to follow-up, one patient refused to submit to further testing, whereas one patient was subsequently diagnosed with acuteonset chronic inflammatory demyelinating polyneuropathy. The remaining 57 (70\%) patients underwent a complete neurological evaluation 1 year after the onset of the disease. After 3 years from the acute GBS episode, five additional patients were lost to follow-up and one died owing to malignancy. However, three patients who were lost at year 1 were retested at year 3 . Thus, the final number of patients tested at year 3 was $54(66 \%)$.

Groups of subjects tested 1 and 3 years after acute phase of GBS were not different between each other and compared with the whole group of 82 patients in terms of neither sociodemographic nor clinical parameters (Table 1).

Poor functional outcome (GDS > 1) was found in $39 \%$ of GBS patients at year 1 and 30\% at year 3 (Figure 2). The presence of sensory disturbances (paresthesias/dysesthesias) was detected in $60 \%$ of our patients after 1 year and $43 \%$ after 3 years, preferably in feet (Table 2). Musculoskeletal pain was present in $40 \%$ of patients at year 1 and $33 \%$ at year 3, and it most commonly presented in the legs. Further on, significant fatigue after 1 year from acute GBS episode was found in $21 \%$ of subjects and after 3 years in only $7 \%$.

Cluster analysis at year 1 showed grouping in two clusters. In cluster 1 (16 patients with more severe findings), poor functional recovery was observed in $69 \%$ of patients, sensory disturbances in $88 \%$, musculoskeletal pain in $100 \%$, and fatigue in $56 \%$ versus $29 \%$ of patients with poor recovery, $46 \%$ with sensory symptoms, $14 \%$ with pain, and $3 \%$ with fatigue in cluster 2 . Cluster analysis at year 3 showed similar results. In cluster 1 (13 patients with more severe findings), poor recovery was observed in $62 \%$ of patients, sensory disturbances in $100 \%$, musculoskeletal pain in $100 \%$, and fatigue in $23 \%$ and in cluster 2 poor recovery was observed in $19 \%$ of patients, sensory symptoms in $24 \%$, pain in $12 \%$, and fatigue in $2 \%$.

Parameters that were proved to be associated with poor functional outcome (GDS $>1$ ) after a 1-year follow-up in our study were age $>55$ years at admission $(p=0.05)$ and severe disability of the disease at admission $(p<0.05)$ and on discharge $(p<0.01)$ (Table 3). Poor functional outcome after 3 years was

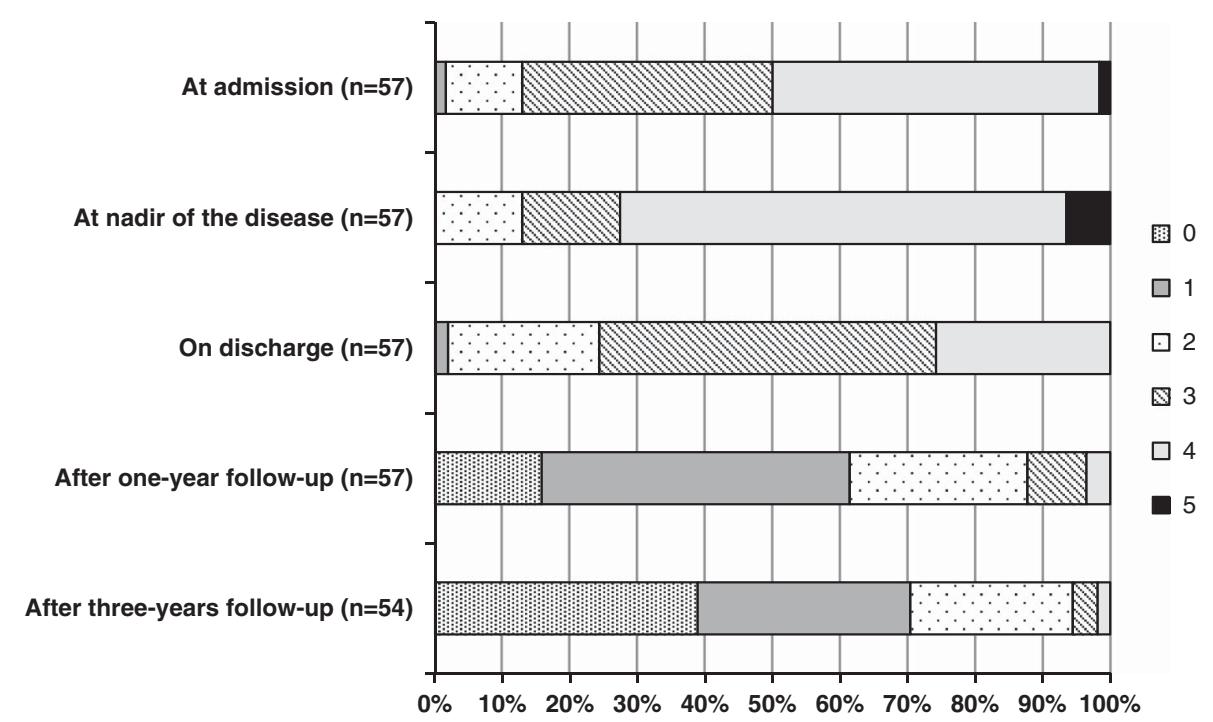

Figure 2: Functional disability in Guillain-Barré syndrome (GBS) patients at admission, at nadir, on discharge, after 1-year follow-up, and after 3-year follow-up according to GDS. GDS $=G B S$ disability scale. 
Table 2: Symptoms in Guillain-Barré syndrome patients after 1- and 3-year follow-up

\begin{tabular}{l|c|c}
\hline Symptom & $\begin{array}{c}\text { Group tested after } \\
\text { 1 year }\end{array}$ & $\begin{array}{c}\text { Group tested after } \\
\text { 3 years }\end{array}$ \\
\hline$n$ & 57 & 54 \\
\hline Paresthesias/dysesthesias & & \\
\hline Present & $60 \%$ & $43 \%$ \\
\hline Mild & $65 \%$ & $52 \%$ \\
\hline Moderate & $26 \%$ & $39 \%$ \\
\hline Severe & $9 \%$ & $9 \%$ \\
\hline Pain & & \\
\hline Present & $40 \%$ & $33 \%$ \\
\hline Mild & $54 \%$ & $72 \%$ \\
\hline Moderate & $27 \%$ & $22 \%$ \\
\hline Severe & $18 \%$ & $6 \%$ \\
\hline Fatigue & & \\
\hline Significant & $21 \%$ & $7 \%$ \\
\hline Average FSS score & $24 \pm 17$ & $17 \pm 12$ \\
\hline
\end{tabular}

$\mathrm{FSS}=$ fatigue severity scale.

associated with male gender $(p<0.05)$ and severe disability on discharge $(p=0.06)$. It is also noteworthy that some clinical features observed 1 year after follow-up can be predictive of worse outcome at year 3-3.3\% of GBS patients with mild disability at year 1 versus $71.4 \%$ of patients with severe disability at year 1 had severe disability at year $3(p<0.01)$; also, $16.7 \%$ of patients without musculoskeletal pain at year 1 versus $52.4 \%$ of patients with musculoskeletal pain at year 1 had severe disability at year $3(p<0.01)$. The presence of sensory disturbances, musculoskeletal pain, and fatigue after 1 and 3 years was not associated with any of the investigated sociodemographic and clinical parameters.

Table 3: Association between sociodemographic/clinical features and poor outcome (GDS $>1$ ) in Guillain-Barré syndrome (GBS) patients after 1 and 3 years of follow-up

\begin{tabular}{l|c|c|c|c}
\hline & \multicolumn{2}{|c|}{$\begin{array}{c}\text { Disability outcome after 1 } \\
\text { year }\end{array}$} & \multicolumn{2}{c}{$\begin{array}{c}\text { Disability outcome after } \\
\text { 3 years }\end{array}$} \\
\hline Feature & $\begin{array}{c}\text { Poor } \\
(\%)\end{array}$ & $\begin{array}{c}\text { Favorable } \\
(\%)\end{array}$ & $\begin{array}{c}\text { Poor } \\
(\%)\end{array}$ & $\begin{array}{c}\text { Favorable } \\
(\%)\end{array}$ \\
\hline Male gender & 70 & 56 & $81^{*}$ & 50 \\
\hline Age (>50 years) & $78^{*}$ & 54 & 75 & 50 \\
\hline $\begin{array}{c}\text { Severe GDS at } \\
\text { admission }\end{array}$ & $67^{*}$ & 37 & 56 & 37 \\
\hline Severe GDS at nadir & 66 & 82 & 69 & 67 \\
\hline $\begin{array}{c}\text { Severe GDS on } \\
\text { discharge }\end{array}$ & $41^{* *}$ & 11 & $31^{\#}$ & 10 \\
\hline
\end{tabular}

GDS $=$ GBS disability scale.

${ }^{*} p<0.05$

$* * p<0.01$

${ }^{*} p=0.06$

\section{DISCUSSION}

Although the current study confirmed that a majority of GBS patients had a benign course of the disease with a favorable outcome, a certain number of subjects still had a significant functional disability after 1 and even after 3 years from acute GBS episode.

In our cohort of 82 patients, three patients died during the hospital stay and four died during a 1-year follow-up period (overall mortality rate of $8.5 \%$ ). These findings are compatible with the literature data reporting lethal outcome in $4 \%-13 \%$ of GBS patients within the first year of follow-up, mostly during the acute progressive phase, and usually caused by cardiologic and respiratory complications. ${ }^{14-17}$

After the 1-year follow-up period, $61 \%$ of patients had no symptoms or had minor symptoms of GBS, $26 \%$ were able to walk independently but unable to run, $9 \%$ were able to walk only with assistance, and $4 \%$ were bedridden or chair bound. Our results are consistent with the current literature reporting that $9 \%-16 \%$ of patients were unable to walk without assistance 1 year after symptom onset. ${ }^{14,15,18}$ After the 3-year follow-up period, $70 \%$ of patients had no symptoms or had minor symptoms of GBS, $24 \%$ were able to walk independently but unable to run, $4 \%$ were able to walk only with assistance, and $2 \%$ were still bedridden or chair bound. Although there are no many studies that followed up GBS patients for 3 or more years, most of them reported favorable recovery in 67 to $100 \%$ of patients..$^{14,17,19-21}$ Furthermore, one recent study on GBS in children reported that after a follow-up period of 11 years, almost all of their patients had a significant recovery (97\%) and only $3 \%$ were able to walk but unable to run. ${ }^{22}$ However, Bersano et $\mathrm{al}^{20}$ showed that around one-third of GBS patients changed their jobs, habits, or social activities, indicating that the impact of GBS on patients' life is not necessarily equal to their residual disability and needs to be carefully analyzed.

Poor functional outcome of GBS after 1 year from acute episode was associated with older age ( $>55$ years), more severe disability at admission and on discharge (i.e., slower recovery in acute phase), whereas poor functional outcome after 3 years was observed in males and in those with slower recovery in acute phase. We also observed that patients with disability and musculoskeletal pain at year 1 from acute episode of GBS had more chance to have disability at year 3 . Previous studies have also analyzed the impact of various factors (age, gender, disease severity, hospital stay duration, duration of intensive care stay, the necessity for artificial ventilation, disease plateau duration) on clinical course and outcome of GBS. The most significant predictors of worse outcome after a wide range of 7 months to more than 7 years after GBS were older age, female gender, greater disability at admission, short interval between symptom onset and admission, and longer duration of plateau phase. ${ }^{16,17,20,23,24}$ Knowing the predictors of the progression and outcome of the disease allows clinicians to identify patients with potentially poor prognosis. This implies early administration of specific immunotherapy, as well as longer rehabilitation time and more frequent neurological follow-ups in order to reach a favorable outcome.

In our cohort, $60 \%$ of patients reported the presence of sensory symptoms (paresthesias/dysesthesias) one year after GBS episode and $43 \%$ after 3 years, with a majority of them having mild symptoms. Lower limbs were more often affected than upper limbs. Residual sensory symptoms were also reported in several studies in $31 \%-75 \%$ of patients 7 months to 11 years after the 
onset of GBS. ${ }^{22,24-26}$ Most of the patients had mild lower limb paresthesias, which is consistent with our findings. $5,24-26$

Musculoskelatal pain was present in $40 \%$ of investigated patients after 1 year of follow-up and in 33\% after 3 years. A majority of patients had mild average pain-54\% after 1 year and $72 \%$ after 3 years. Similar results were found in former studies, which registered mostly musculoskeletal pain but also other types of pain (neuropathic, painful paresthesias, meningism) in 33\%-38\% of patients, 1-2 years after disease onset. ${ }^{27-29}$ Bernsen et $\mathrm{al}^{26}$ reported a higher number, $48 \%$, of patients who had pain from 3 to 6 years after GBS onset, most prominently in the form of muscle aches. Although most of our patients reported minor pain, pain could be a permanent health problem and might highly affect functionality and quality of life of the patients. ${ }^{27,30}$ Pain as a residue of GBS can frequently be neuropathic, which is of importance in differential diagnosis. Therefore, it is very important to recognize and differentiate neuropathic and musculoskeletal pain in GBS, which directs clinicians toward proper cure. Considering poorly understood and potentially multifactorial etiology of different pain types in GBS patients, ${ }^{27}$ it is necessary to conduct further studies to analyze the impact of various factors that could contribute to the presence and endurance of pain during the acute phase of the disease, as well as during a recovery period.

Our study revealed that one out of five patients of our cohort reported significant fatigue 1 year after symptom onset, whereas $7 \%$ of them had fatigue after 3 years. Many studies so far have shown that fatigue is one of the most disabling symptoms in GBS patients and that it could seriously affect both their functionality and quality of life. ${ }^{31-33}$ Further on, after 1 to 20 years of followup period, fatigue was detected in $22 \%-42 \%$ of GBS patients, ${ }^{22,34,35}$ confirming its status as one of the most important post-GBS sequela. Moreover, Drory et $\mathrm{al}^{33}$ showed that fatigue can persist and remain severe in a significant number of patients for many years after onset, in spite of making a good neurological recovery. Although etiology of fatigue remains elusive, there are some presumptions about the role of post-traumatic stress disorder as a consequence of severe neurological disease with a potentially lethal outcome. However, Rekand et $\mathrm{al}^{35}$ have found that the risk of occurrence of fatigue is twice as higher in patients with residual weakness, partially explained by muscle dysfunction. The presence of fatigue can substantially affect quality of life in patients with GBS and it could potentially be treated with medications, physical therapy, and cognitive-behavioral therapy. ${ }^{31,36-39}$ Therefore, it is of great importance to evaluate fatigue in early stages and treat them timely with an appropriate therapy.

The main limitation of our study is a relatively small sample size that limited the number of statistical comparisons owing to possible false positive results. We are eagerly waiting data from the multi-centric IGOS study on more than 1000 patients. Another limitation is lack of data on sensory symptoms, musculoskeletal pain, and fatigue at the time of hospitalization. Finally, we had a relatively large number of patients lost to follow-up that can cause selection bias toward more severe cases that needed further medical assistance and thus came to check-up visits. On the other hand, it is also possible that some patients who were lost to follow-up actually passed away.

In conclusion, although GBS typically has a monophasic course and good outcome, a certain number of patients can have significant residual functional disability. After $1 / 3$ years from GBS acute episode, $26 \% / 24 \%$ of patients were unable to run, $9 \% / 4 \%$ walked only with assistance, and $4 \% / 2 \%$ were bedridden or chair bound. The presence of sensory symptoms (paresthesias/ dysesthesias) was detected in $60 \%$ of subjects after 1 year and in $43 \%$ after 3 years, whereas pain was present in $40 \% / 33 \%$ of patients and fatigue in $21 \% / 7 \%$. All these disturbances may significantly affect patients' quality of life.

\section{ACKNOWLEDGMENTS}

This study was supported by the Ministry of Education, Science and Technological Development of Serbia (grant \#175083).

\section{DisClosures}

The authors do not have anything to disclose.

\section{REFERENCES}

1. Kuwabara S. Guillain-Barré syndrome: epidemiology, pathophysiology and management. Drugs. 2004;64(6):597-610.

2. Hughes RAC, Cornblath DR. Guillain-Barré syndrome. Lancet. 2005;366(9497):1653-66.

3. Wim Ang C, Jacobs BC, Laman JD. The Guillain-Barré syndrome: a true case of molecular mimicry. Trends Immunol. 2004;25(2):61-6.

4. Peric S, Milosevic V, Berisavac I, et al. Clinical and epidemiological features of Guillain-Barré syndrome in the Western Balkans. J Peripher Nerv Syst. 2014;19(4):317-21.

5. Bernsen RA, de Jager AE, van der Meché FG, Suurmeijer TP. How Guillain-Barre patients experience their functioning after 1 year. Acta Neurol Scand. 2005;112(1):51-6.

6. Hartung HP, van der Meché FG, Pollard JD. Guillain-Barré syndrome, CIDP and other chronic immune-mediated neuropathies. Curr Opin Neurol. 1998;11(5):497-513.

7. Merkies IS, Schmitz PI, Samijn JP, van der Meché FG, van Doorn PA. Fatigue in immune-mediated polyneuropathies. European Inflammatory Neuropathy Cause and Treatment (INCAT) Group. Neurology. 1999;53(8):1648-54.

8. Sejvar JJ, Kohl KS, Gidudu J, et al. Guillain-Barré syndrome and Fisher syndrome: case definitions and guidelines for collection, analysis, and presentation of immunization safety data. Vaccine. 2011;29(3):599-612.

9. Uncini A, Kuwabara S. Electrodiagnostic criteria for Guillain-Barrè syndrome: a critical revision and the need for an update. Clin Neurophysiol. 2012;123(8):1487-95.

10. Dimachkie MM, Barohn RJ. Guillain-Barré syndrome and variants. Neurol Clin. 2013;31(2):491-510.

11. Hughes RA, Newsom-Davis JM, Perkin GD, Pierce JM. Controlled trial prednisolone in acute polyneuropathy. Lancet. 1978; 2(8093):750-3.

12. Krupp LB, LaRocca NG, Muir-Nash J, Steinberg AD. The fatigue severity scale. Application to patients with multiple sclerosis and systemic lupus erythematosus. Arch Neurol. 1989;46(10):1121-3.

13. Peric M, Peric S, Rapajic N, et al. Multidimensional aspects of pain in myotonic dystrophies. Acta Myol. 2015;34(2-3):126-32.

14. Rees JH, Thompson RD, Smeeton NC, Hughes RA. Epidemiological study of Guillain-Barré syndrome in south east England. J Neurol Neurosurg Psychiatry. 1998;64(1):74-7.

15. van den Berg B, Bunschoten C, van Doorn PA, Jacobs BC. Mortality in Guillain-Barre syndrome. Neurology. 2013;80(18):1650-4.

16. Rajabally YA, Uncini A. Outcome and its predictors in Guillain-Barré syndrome. J Neurol Neurosurg Psychiatry. 2012;83(7):711-8.

17. Winer JB, Hughes RA, Osmond C. A prospective study of acute idiopathic neuropathy. I. Clinical features and their prognostic value. J Neurol Neurosurg Psychiatry. 1988;51(5):605-12.

18. Kaida K. [Prognostic factors in Guillain-Barré syndrome]. Rinsho Shinkeigaku. 2013;53(11):1315-8.

19. Dornonville de la Cour C, Jakobsen J. Residual neuropathy in longterm population-based follow-up of Guillain-Barré syndrome. Neurology. 2005;64(2):246-53.

20. Bersano A, Carpo M, Allaria S, Franciotta D, Citterio A, NobileOrazio E. Long term disability and social status change after Guillain-Barré syndrome. J Neurol. 2006;253(2):214-8. 
21. Chiò A, Cocito D, Leone M, Giordana MT, Mora G, Mutani R. Guillain-Barré syndrome: a prospective, population-based incidence and outcome survey. Neurology. 2003;60(7):1146-50.

22. Roodbol J, de Wit M-CY, Aarsen FK, Catsman-Berrevoets CE, Jacobs BC. Long-term outcome of Guillain-Barré syndrome in children. J Peripher Nerv Syst. 2014;19(2):121-6.

23. Khan F, Pallant JF, Ng L, Bhasker A. Factors associated with long-term functional outcomes and psychological sequelae in Guillain-Barre syndrome. J Neurol. 2010;257(12):2024-31.

24. Koeppen S, Kraywinkel K, Wessendorf TE, et al. Long-term outcome of Guillain-Barré syndrome. Neurocrit Care. 2006;5(3):235-42.

25. Bernsen RA, de Jager AE, Schmitz PI, van der Meché FG. Long-term impact on work and private life after Guillain-Barré syndrome. J Neurol Sci. 2002;201(1-2):13-7.

26. Bernsen RA, Jager AE, Schmitz PI, van der Meché FG. Long-term sensory deficit after Guillain-Barré syndrome. J Neurol. 2001; 248(6):483-6.

27. Farmakidis C, Inan S, Milstein M, Herskovitz S. Headache and pain in Guillain-Barré syndrome. Curr Pain Headache Rep. 2015; 19(8):40.

28. Ruts L, Drenthen J, Jongen JLM, et al. Pain in Guillain-Barre syndrome: a long-term follow-up study. Neurology. 2010;75(16):1439-47.

29. Forsberg A, Press R, Einarsson U, de Pedro-Cuesta J, Widén Holmqvist L. Impairment in Guillain-Barré syndrome during the first 2 years after onset: a prospective study. J Neurol Sci. 2004;227(1):131-8.

30. Mullings KR, Alleva JT, Hudgkins TH. Rehabilitation of GuillainBarré syndrome. Disease Month. 2010;56(5):288-92.
31. Merkies ISJ, Kieseier BC. Fatigue, pain, anxiety and depression in Guillain-Barré syndrome and chronic inflammatory demyelinating polyradiculoneuropathy. Eur Neurol. 2016;75(3-4):199-206.

32. Merkies ISJ, Faber CG. Fatigue in immune-mediated neuropathies. Neuromuscul Disord. 2012;22:S203-7.

33. Drory VE, Bronipolsky T, Bluvshtein V, Catz A, Korczyn AD. Occurrence of fatigue over 20 years after recovery from GuillainBarré syndrome. J Neurol Sci. 2012;316(1-2):72-5.

34. Witsch J, Galldiks N, Bender A, et al. Long-term outcome in patients with Guillain-Barré syndrome requiring mechanical ventilation. J Neurol. 2013;260(5):1367-74.

35. Rekand T, Gramstad A, Vedeler CA. Fatigue, pain and muscle weakness are frequent after Guillain-Barré syndrome and poliomyelitis. J Neurol. 2009;256(3):349-54.

36. Khan F, Amatya B. Rehabilitation interventions in patients with acute demyelinating inflammatory polyneuropathy: a systematic review. Eur J Phys Rehabil Med. 2012;48(3):507-22.

37. Garssen MPJ, Bussmann JBJ, Schmitz PIM, et al. Physical training and fatigue, fitness, and quality of life in Guillain-Barré syndrome and CIDP. Neurology. 2004;63(12):2393-5.

38. de Vries JM, Hagemans MLC, Bussmann JBJ, van der Ploeg AT, van Doorn PA. Fatigue in neuromuscular disorders: focus on GuillainBarré syndrome and Pompe disease. Cell Mol Life Sci. 2010; 67(5):701-13.

39. Cesarini M, Angelucci E, Foglietta T, Vernia P. Guillain-Barrè syndrome after treatment with human anti-tumor necrosis factor $\alpha$ (adalimumab) in a Crohn's disease patient: case report and literature review. J Crohns Colitis. 2011;5(6):619-22. 